Annales Geophysicae (2004) 22: 1149-1153

SRef-ID: $1432-0576 / \mathrm{ag} / 2004-22-1149$

(C) European Geosciences Union 2004

\title{
Velocity shear-related ion upflow in the low-altitude ionosphere
}

\author{
H. Liu ${ }^{1}$ and G. $\mathrm{Lu}^{2}$ \\ ${ }^{1}$ GeoForschungsZentrum Potsdam, Telegrafenberg, Potsdam, Germany \\ ${ }^{2}$ High Altitude Observatory, NCAR, Boulder, CO, USA
}

Received: 1 February 2003 - Revised: 29 October 2003 - Accepted: 17 November 2003 - Published: 2 April 2004

\begin{abstract}
Strong ion upflows with field-aligned velocity above $1000 \mathrm{~ms}^{-1}$ were observed by the European Incoherent Scatter (EISCAT) UHF Radar at Troms $\emptyset$, Norway in the dayside auroral region at heights between $500-600 \mathrm{~km}$ during the 15 May 1997 magnetic storm. Both the EISCAT observations and the Assimilative Mapping of Ionospheric Electrodynamics (AMIE) simulation results show that this event occurred in a region with low Joule heating rate, but with strong velocity shear. During the same period, the electron density and temperature showed no sign of soft particle precipitation, which is consistent with the UVI images from the POLAR satellite, thus excluding possible ion energization through soft particle precipitation. Our simple calculation shows that the velocity shear can provide sufficient energy for the observed ion upflow, thus suggesting shear-driven instabilities as a possible heating mechanism.
\end{abstract}

Key words. Ionosphere, particle acceleration, magnetospheric physics

\section{Introduction}

Upward flowing ionospheric ions have been recognized as an important part of the ionosphere-magnetosphere coupling in recent years. They are observed at various magnetic local times and altitudes from a few hundred kilometers to several Earth radii $\left(R_{e}\right)$, by both ground-based radars and satellites (Yau et al., 1985; Lockwood et al., 1985; Loranc et al., 1991; Liu et al., 2001; Fujii et al., 2002). Various mechanisms have been proposed for ion energization. Frictional heating, such as Joule heating, is often considered to be the energy source for ion upflows at F-region heights (Keating et al., 1990). But the distribution function sometimes reveals perpendicular ion heating that cannot be accounted for by frictional heating alone, thereby indicating the presence of wave heating via plasma instabilities (Whalen et al., 1991). Current-driven in-

Correspondence to: $\mathrm{H}$. Liu

(huixin@gfz-potsdam.de) stabilities (i.e. Buneman instability, ion cyclotron instability, and ion-acoustic instability) are considered to be important energy sources (Ungstrup et al., 1979; Forme et al., 1993). These mechanisms, however, generally cannot operate at altitudes below $1000 \mathrm{~km}$ (Forme et al., 1993; Ganguli et al., 1994). On the other hand, energization must take place at low altitudes if we are to explain the fluxes, energies, and composition of ion flows observed at high altitudes. Therefore, there is a real need for a low-altitude ion energization mechanism.

Soft particle precipitation has been recognized as another important source for ion energization at low altitudes. By using simultaneous EISCAT Svalbard Radar (ESR) and EISCAT VHF observations, Ogawa et al. (2000) found that ion upflows are associated with a significant anisotropy of the ion temperature, isotropic increases of the electron temperature, and soft particle precipitation. A good correlation between ion outflows and auroral precipitation has been reported recently by Tung et al. (2001) near the nightside polar cap boundary. Liu et al. (1995) demonstrated by using simulations that soft electron precipitation can rapidly enhance the F-region ionization and the electron temperature, leading to a strong upward plasma expansion.

Studies of velocity shear-driven instabilities suggest the existence of other mechanisms. Simulation of electrostatic turbulence due to sheared flows transverse to the magnetic field shows that velocity shears can lower the threshold values for the field-aligned current-driven instabilities to excite electrostatic waves, thus energizing ions at lower altitudes (Ganguli et al., 1988; Nishikawa et al., 1990). Romero et al. (1992) reported the occurrence of a coherent structure (vortex-like) of the electric field potential and significant resonant ion acceleration in the nonlinear evolution of lower hybrid instabilities. The growing waves are associated with small vortices in the linear stage, which evolves into a nonlinear state dominated by larger vortices with lower hybrid frequencies, becoming a potential source for ion heating.

Ion upflow associated with velocity shears has been reported in Hilat satellite observations in the cusp/cleft region 


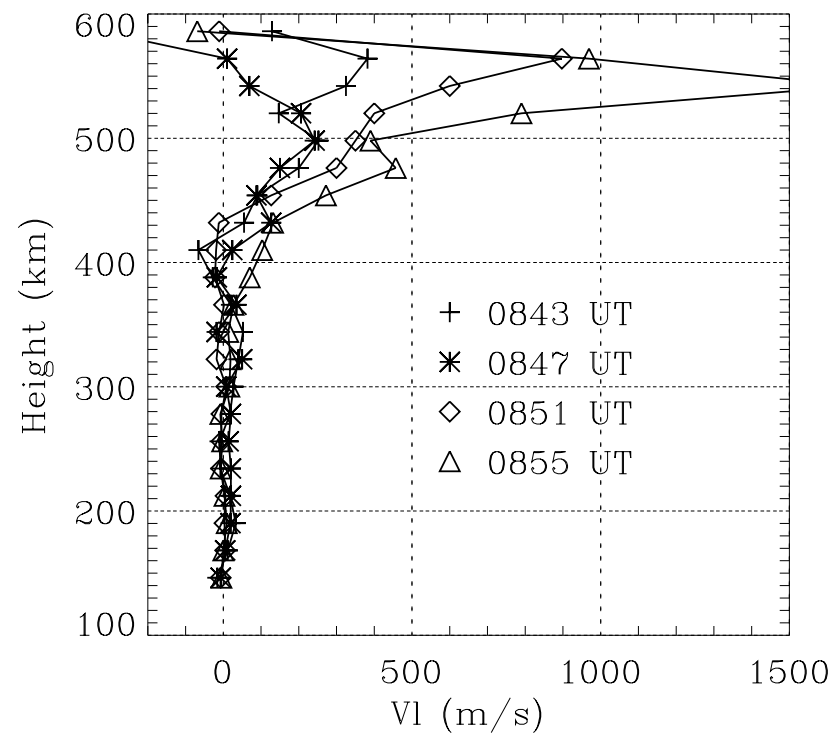

Fig. 1. The height profile of the field-aligned ion velocity at four consecutive times on 15 May 1997. Positive means upward.

at $800 \mathrm{~km}$ altitude (Tsunoda et al., 1989). To further examine the plausibility of the shear-related ion energization mechanism, we present a case study of a strong ion upflow observed by EISCAT radar at an altitude range between $500-600 \mathrm{~km}$ on 15 May 1997. Convection patterns derived from the Assimilative Mapping of Ionospheric Electrodynamics (AMIE) procedure show that this ion upflow occurred near a convection vortex where a strong velocity shear was observed. Calculation of the shear energy shows that it can provide sufficient energy for the observed ion upflows.

\section{Radar Observations}

The EISCAT Troms $\varnothing$ UHF radar is located at $69.7^{\circ} \mathrm{N}$ geog. $\left(66^{\circ} \mathrm{N}\right.$ geom.). Four parameters are routinely derived from the radar observations, namely, the electron density, the electron and ion temperature, and the line-of-sight ion velocity. The line-of-sight ion velocity measured approximately along the local geomagnetic field direction is generally referred to as the field-aligned ion velocity at F-region heights. The $\boldsymbol{E} \times \boldsymbol{B}$ drift velocity can be determined by a tri-station measurement. Detailed descriptions of the EISCAT radar system can be found in Rishbeth and van Eyken (1993).

The 15 May geomagnetic storm started at 01:59 UT with a storm sudden commencement. The $D_{s t}$ index reached a minimum of $-120 \mathrm{nT}$ at 12:00 UT, and the $A E$ value was about $2000 \mathrm{nT}$ at 12:35 UT. The ion upflow burst studied here occurred during 08:43-08:55 UT, which was during the main phase of the magnetic storm, with increasing duskward IMF $B_{y}$ and relatively stable southward IMF $B_{z}$.

Figure 1 presents the height profile of the field-aligned ion velocity observed at four consecutive times. From 08:43 UT, the upward field-aligned ion velocity showed continuous increase at altitudes above $400 \mathrm{~km}$. It reached more than
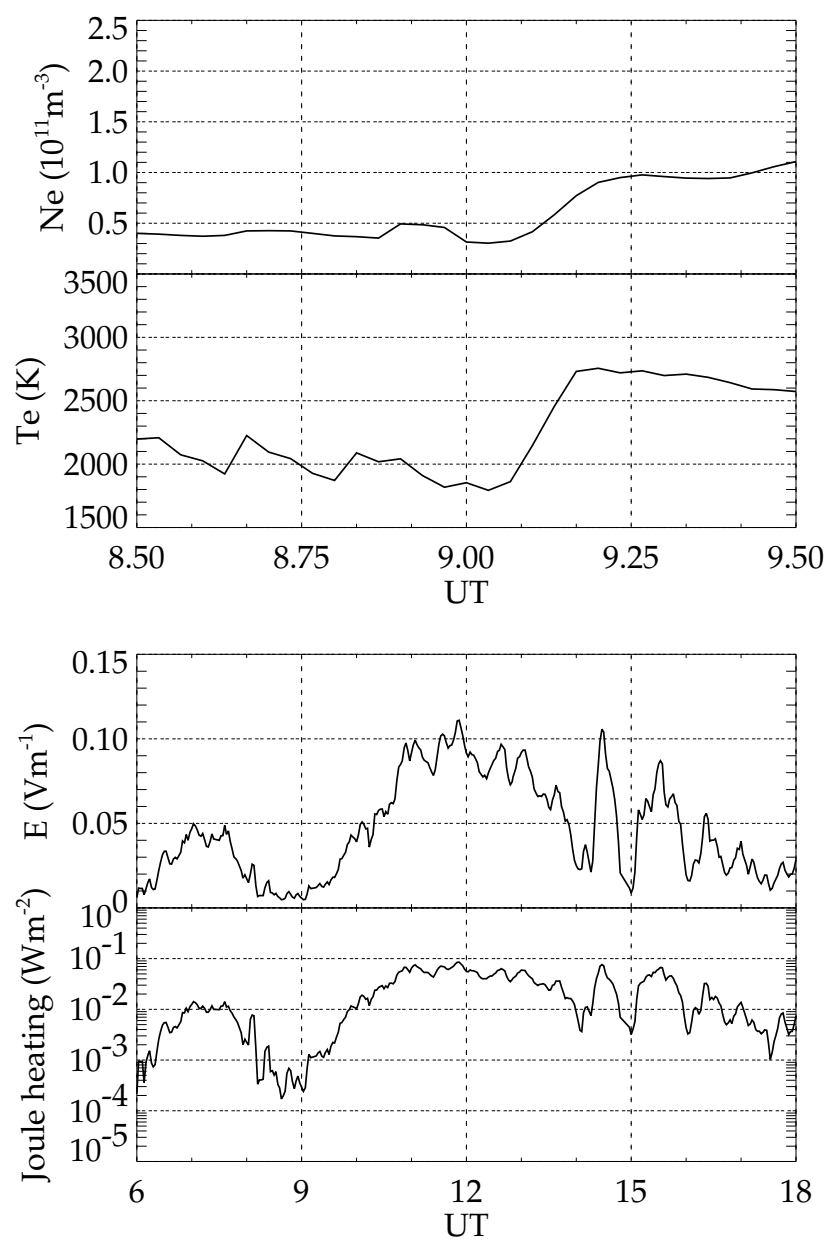

Fig. 2. The EISCAT measurements on 15 May 1997. The first and second panels show the electron density and temperature averaged between 350-600 km during 08:30-09:30 UT. The third and fourth panels show the electric field and the Joule heating during 06:0018:00 UT. $\mathrm{LT}=\mathrm{UT}+1 \mathrm{~h} ; \mathrm{MLT}=\mathrm{UT}+2.4 \mathrm{~h}$.

$1000 \mathrm{~ms}^{-1}$ at $550 \mathrm{~km}$ altitude at 08:55 UT, which is very unusual at this altitude. The velocity dropped to values below $200 \mathrm{~ms}^{-1}$ afterwards. The electron density and temperature averaged over 350-600 km during 08:30-09:30 UT are shown in the first two panels of Fig. 2. They showed no sign of large enhancements before 09:00 UT, indicating the lack of soft particle precipitations (Millward et al., 1999). The Joule heating rate calculated from the EISCAT measurements (Davies et al., 1997) is shown in the bottom panel of Fig. 2. Note that the Joule heating rate dropped below $1 \mathrm{mWm}^{-2}$ between 08:30-09:00 UT.

Figure 3 shows the clockdial plot of the ion drift velocity perpendicular to the geomagnetic field measured by EISCAT. During the $24 \mathrm{~h}$ period, ion drifts at EISCAT experienced several changes. The drift speed was below $50 \mathrm{~ms}^{-1}$ between 00:00 and 07:00 LT (except for one outlier at $\sim$ 03:00 LT, which is not of interest to this study), but reached more than $1500 \mathrm{~ms}^{-1}$ during 13:00-17:00 LT. A large velocity reversal occurred around 10:00 LT ( 09:00 UT) when the ion drift rotated from poleward to equatorward, coinciding with the strong ion upflows observed by EISCAT. 
ION VELOCITY PERP. TO GEOMAGNETIC FIELD

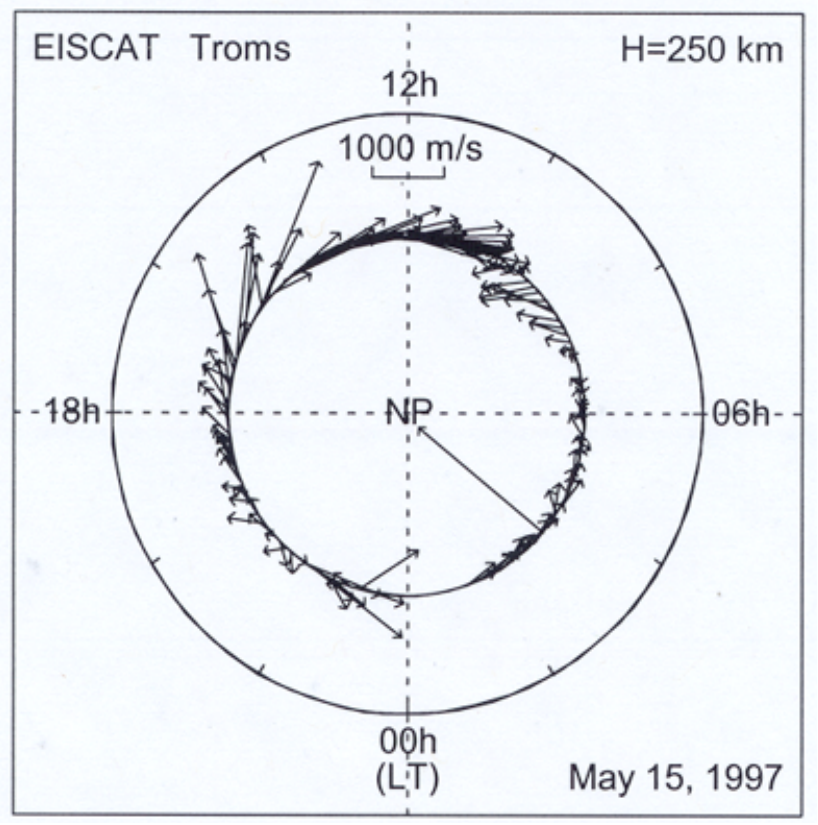

Fig. 3. The ion velocity perpendicular to the geomagnetic field observed by EISCAT. A significant reversal occurred around 10:00 LT. $\mathrm{LT}=\mathrm{UT}+1 \mathrm{~h}$.

\section{AMIE Results}

The AMIE technique is used to derive the snapshots of largescale ionospheric convection patterns and other electrodynamic parameters, such as field-aligned currents (Richmond and Kamide, 1988). Data inputs for this particular event include a global network of ground magnetometers (121 in total), the SuperDARN radars, and global auroral images from the Polar UVI (see Lu et al. (1998) for more details and references). Figure 4 shows the convection patterns derived from AMIE for the period of 08:40-09:05 UT on 15 May 1997. One can see that the EISCAT radar (represented by the letter "E" on the convection maps) was located near the center of a convection vortex at about 11:00 MLT, which later merged with the duskside convection cell. This is fully consistent with the convection velocity measurements from EISCAT shown in Figure 3. We should note that during this time interval two of the SuperDARN radars in Pykkvibaer and Hankasalmi did not obtain sufficient back scatters over the Troms $\varnothing$ region. The small convection vortex shown in the AMIE convection maps was determined mainly by ground magnetometers over the Scandinavian region, along with ionospheric conductances derived from global auroral images. The AMIE results also show that the convection vortex is associated with upward field-aligned currents, with a maximum current density of $\sim 1.0 \mu \mathrm{Am}^{-2}$.

\section{Discussion}

Three mechanisms have been proposed for ion energization at $F$ region heights, namely, Joule heating, soft particle precipitation, and velocity shear. As shown in Fig. 2, the Joule heating rate during the period of 08:30-09:00 UT was very low, actually close to the minimum value for the day. Therefore, it is unlikely to be the direct source for the observed upflowing ions. The low electron density and temperature in the F-region indicated that no soft particle precipitation occurred during this period. This is further corroborated by the UVI images from the POLAR satellite, showing that EISCAT was located equatorward of a very faint dayside aurora at the time when the intense ion upflow was observed. These evidences thus exclude possible heating by soft particle precipitations.

Field-aligned current-driven instabilities have also been proposed to be a possible mechanism (Ungstrup et al., 1979; Satyanarayana et al., 1985; Forme et al., 1993). However, the maximum field-aligned current density derived from both the EISCAT observation (the divergence of the horizontal current) and the AMIE procedure during 08:30-09:00 UT was only about $1.0 \mu \mathrm{Am}^{-2}$. This value is much lower than the approximate $20 \mu \mathrm{Am}^{-2}$ threshold required to excite $\mathrm{O}^{+}$ion cyclotron waves at these altitudes (Satyanarayana et al., 1985). Therefore, the field-aligned current-driven instabilities cannot be directly invoked for the transverse heating in this case.

As mentioned in the Introduction, studies of velocity shear-driven instabilities have shed light on the existence of new mechanisms for ion energization at low altitudes. Ganguli et al. (1994) demonstrated theoretically that even a small amount of velocity shear in the transverse flow is sufficient to excite a large-scale Kelvin-Helmholtz mode, which can nonlinearly steepen and give rise to plasma waves in the range of ion cyclotron to lower hybrid frequencies. These waves are potential sources for ion heating (Walker et al., 1997; Amatucci et al., 1998). Another possibility is that the velocity shear can lower the threshold for fieldaligned current-driven instabilities to excite ion cyclotron waves, thereby heating the ions at low altitudes (Nishikawa et al., 1990). According to Ganguli et al. (1994), the power density transferred by the instabilities to the $\mathrm{O}^{+}$ions from the convection flow is $P \approx 2.7 \times 10^{-4} \beta \omega \mathrm{J} \mathrm{m}^{-2} \mathrm{~s}^{-1}$. The growth rate (or frequency) of the instability $\omega$ is generally above $10^{2} \mathrm{~s}^{-1}$. And $\beta=\Delta V_{i} / V_{i}$, where $V_{i}$ is the average velocity of the convective flows and $\Delta V_{i}$ is the average change of its velocity due to dissipation by instabilities. Taking the growth rate $\omega$ as low as $\sim 10^{2} \mathrm{~s}^{-1}$, we obtain $P \approx 2.7 \times 10^{-2} \beta \mathrm{J} \mathrm{m}^{-2} \mathrm{~s}^{-1}$. Assuming that any change in the convective velocity from its steady state value is restored to its original or a new steady-state value via instabilities, we roughly calculate $\Delta V_{i}$ as the product of the wave growth time $\left(\sim 10^{-2} \mathrm{~s}\right)$ and the average changing rate of the convective velocity $\left(\sim 2 \mathrm{~m} \mathrm{~s}^{-2}\right.$ from Fig. 3$)$. This yields an estimate of $\Delta V_{i}$ to be $2 \times 10^{-2} \mathrm{~m} \mathrm{~s}^{-1}$. Taking the average $V_{i}$ during 08:40-09:00 UT as $500 \mathrm{~m} \mathrm{~s}^{-1}$, we then obtain the value of $\sim 4 \times 10^{-5}$ for $\beta$ during the corresponding period. Therefore, we have $P \approx 1.1 \times 10^{-6} \mathrm{~J} \mathrm{~m}^{-2} \mathrm{~s}^{-1}$. This is more than ten times higher than the power density needed for accelerating the observed upflowing ions, which is approximately $8.4 \times 10^{-8} \mathrm{~J} \mathrm{~m}^{-2} \mathrm{~s}^{-1}$ (taking the average ion density during 08:40-09:00 UT to be $\sim 5 \times 10^{10} \mathrm{~m}^{-3}$ and the average field-aligned ion velocity to be $\sim 500 \mathrm{~m} \mathrm{~s}^{-1}$ ). Therefore, the 

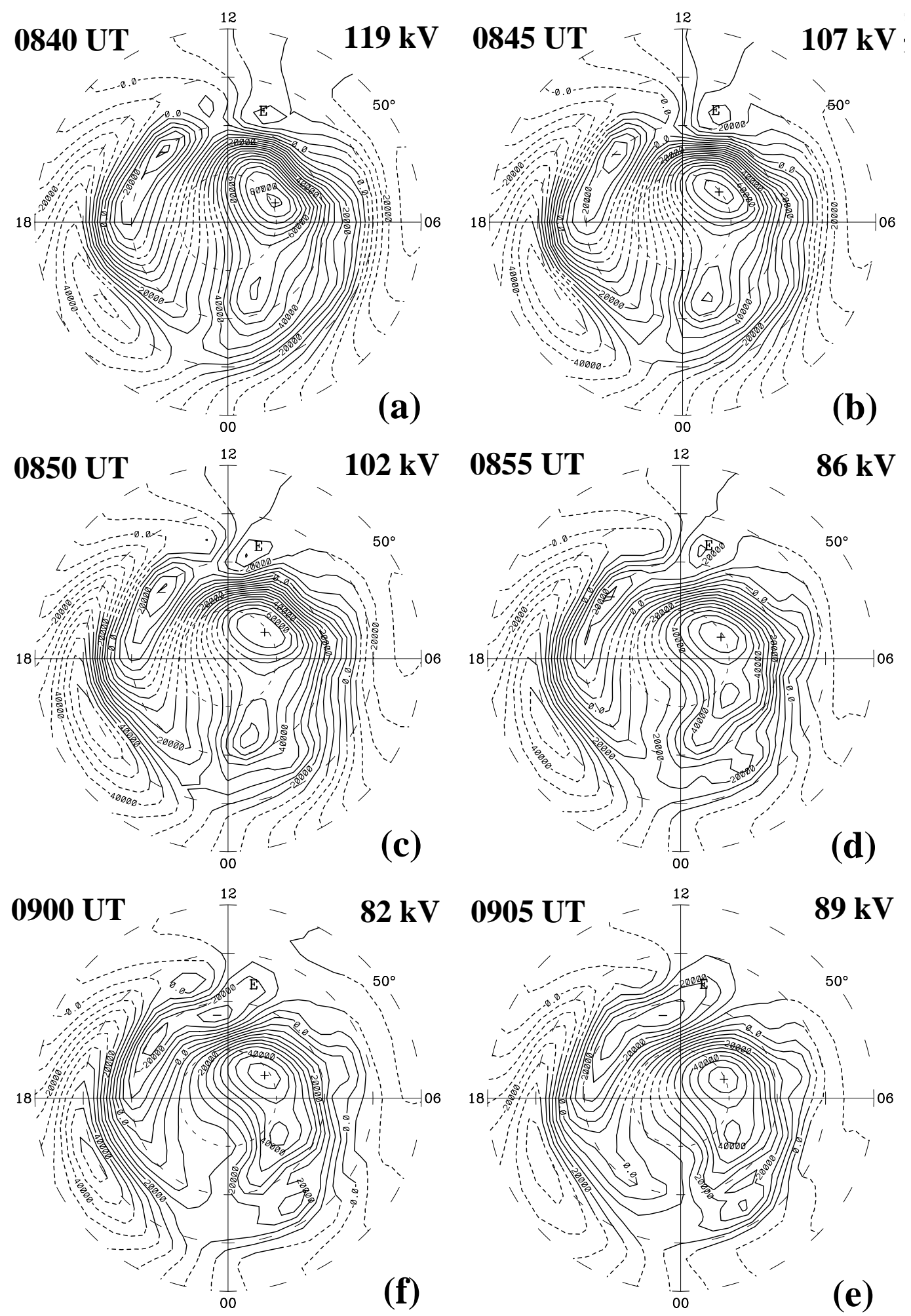

Fig. 4. Convection patterns on 15 May 1997 derived from AMIE. The letter "E" represents the location of EISCAT (near 11:00 MLT). The convection contours are shown as solid lines where the AMIE procedure infers an uncertainty in the large-scale electric field of less than $50 \%$, and as dashed lines where the uncertainty exceeds $50 \%$. 
velocity shear was able to provide sufficient energy for the ion upflow burst during this event.

Velocity shear-related ion upflows have also been observed by other radars (i.e. Sondrestrom radar) at F-region heights (Semester et al., 2003). Similar analysis of energy involved in these events is expected to further elucidate the energization mechanism via velocity shear.

Acknowledgements. We thank S.-Y. Ma for helpful discussions. We are grateful to the director and staff of EISCAT for operating the facility and supplying the data. EISCAT is an international association supported by Finland (SA), France (CNRS), Germany (MPG), Japan (NIPR), Norway (NFR), Sweden (NFR), and the United Kingdom (PPARC). The operation of the SuperDARN radars in the Norhtern Hemisphere is supported by the national funding agencies of the US, Canada, and France. We are very grateful to M. Ruohoniemi at JHU/APL for preparing the radar data. The Polar UVI data was prepared and provided by D. Lummerzheim at University of Alaska at Fairbanks. Work at HAO/NCAR was supported by the NASA SEC Theory and Guest Investigator programs.

Topical Editor M. Lester thanks A. Yau for his work in evaluating this paper.

\section{References}

Amatucci, W. E., Walker, D. N., Ganguli, G., Duncan, D., Antoniades, J. A., Bowles, J. H., Gavrishchaka, V., and Koepke, M. E.: Velocity-shear-driven ion-cyclotron waves and associated transverse ion heating, J. Geophys. Res. 103, 11 711-11 724, 1998.

Davies, J. A., Lester, M., and McCrea, I. W.: A statistical study of ion frictional heating observed by EISCAT, Ann. Geophysicae, 15, 1399-1411, 1997.

Forme, F. R. E., Wahlund, J.-E., Opgenoorth, H. J., Persson, M. A. L., and Mishin, E. V.: Effects of current driven instabilities on the ion and electron temperatures in the topside ionosphere, $\mathrm{J}$. Atmos. Terr. Phys., 55, 647-666, 1993.

Fujii, R., Oyama, S., Buchert, S. C., Nozawa, S., and Matuura, N.: Field-aligned ion motions in the E- and F-region, J. Geophys. Res., 107, 10.1029/2001JA900148, 2002.

Ganguli, G. and Palmadesso, P. J.: Electrostatic ion instabilities in the presence of parallel currents and transverse electric fields, Geophys. Res. Lett., 15, 103-106, 1988.

Ganguli, G., Keskinen, M. J., Romero, H., Heelis, R., Moore, T., and Pollock, C.: Coupling of microprocesses and macroprocesses due to velocity shear: an application to the low-altitude ionosphere, J. Geophys. Res., 99, 8873-8889, 1994.

Keating, J. G., Mulligan, F. J., Doyle, D. B., Winser, K. J., and Lockwood, M.: A statistical study of large field-aligned flows of thermal ions at high-latitudes, Planet. Space Sci., 38, 1187-1201, 1990.

Liu, C., Horwitz, J. L., and Richards, P. G.: Effects of frictional heating and soft-electron precipitation on high-latitude F-region upflows, Geophys. Res. Lett., 22, 2713-2716, 1995.

Liu, H., Ma, S.-Y., and Schlegel, K.: Diurnal, seasonal, and geomagnetic variation of large field-aligned ion upflows in the highlatitude ionospheric F region J. Geophys. Res., 106, 24651$24661,2001$.

Lockwood, M., Waite, J. H., Moore, T. E., Johnson, J. F. E., and Chappell, C. R.: A new source of suprathermal $\mathrm{O}^{+}$ions near the dayside polar cap boundary, J. Geophys. Res., 90, 4099-4116, 1985.
Loranc, M., Hanson, W. B., Heelis, R. A., and St.-Maurice, J.-P.: A morphological study of vertical ionospheric flows in the highlatitude F region, J. Geophys. Res. 96, 3627-3646, 1991.

Lu, G., Baker, D. N., McPherron, R. L., Farrugia, C. J., Lummerzheim, D., Ruohoniemi, J. M., Rich, F. J., Evans, D. S., Lepping, R. P., Brittnacher, M., Li, X., Greenwald, R., Sofko, G., Villain, J., Lester, M., Thayer, J., Moretto, T., Milling, D., Troshichev, O., Zaitzev, A., Odintzov, V., Makarov, G., and Hayashi, K.: Global energy deposition during the January 1997 magnetic cloud event, J. Geophys. Res., 103, 11 685-11694, 1998.

Millward, G. H., Moffett, R. J., and Balmforth, H. F.: Modeling the ionospheic effects of ion and electron precipitation in the cusp, J. Geophys. Res., 104, 24 603-24 612, 1999.

Nishikawa, K.-I., Ganguli, G., Lee, Y. C., and Palmadesso, P. J.: Simulation of electrostatic turbulence due to sheared flows parallel and transverse to the magnetic field, J. Geophys. Res., 95, 1029-1038, 1990.

Ogawa, Y., Fujii, R., Buchert, S. C., and Nozawa, S.: Simultaneous EISCAT Svalbard and VHF radar observations of ion upflows at different aspect angles, Geophys. Res. Lett., 27, 81-84, 2000.

Richmond, A. D. and Kamide, Y.: Mapping electrodynamic features of the high-latitude ionosphere from localized observations, Technique, J. Geophys. Res., 93, 5741-5759, 1988.

Rishbeth, H. and van Eyken, A. P.: EISCAT: early history and the first ten years of operation, J. Atmos. Terr. Phys., 55, 525-542, 1993.

Romero, H., Ganguli, G., and Lee, Y. C.: Ion acceleration and coherent structures generated by lower hybrid shear-driven instabilities, Phys. Rev. Lett., 69, 3503-3506, 1992.

Satyanarayana, P., Chaturvedi, P. K., Keskinen, M. J., Huba, J. D., and Ossakow, S. L.: Theory of current driven ion cyclotron instability in the bottomside ionosphere, J. Geophys. Res., 90, 12 209-12 218, 1985.

Semester, J., Heinselman, C. J., Thayer, J. P., Doe, R. A., and Frey, H. U.: Ion upflow enhanced by drifting F-region plasma structure along the nightside polar cap boundary, Geophys. Res. Lett., Vol. 30, NO. 22, 2139, doi:10.1029/2003GL017747, 2003.

Tsunoda, R. T., Livingston, R. C., Vickrey, J. F., Heelis, R. A., Hanson, W. B., Rich, F. J., and Bythrow, P. F.: Dayside observations of thermal-ion upwellings at $800-\mathrm{km}$ altitude: an ionospheric signature of the cleft ion fountain, J. Geophys. Res., 94, 15 277-15 290, 1989.

Tung, Y.-K., Carlson, C. W., McFadden, J. P., Klumpar, D. M., Parks, G. K. , Peria, W. J., and Liou, K.: Auroral polar cap boundary ion conic outflow observed on FAST, J. Geophys. Res., 106, 3603-3614, 2001.

Walker, D. N., Amatucci, W. E., Ganguli, G., Antoniades, J. A., Bowles, J. H., Duncan, D., Gavrishchaka, V., and Koepke, M. E.: Perpendicular ion heating by velocity-shear-driven waves, Geophys. Res. Lett., 24, 1187-1190, 1997.

Whalen, B. A., Watanabe, S., and Yau, A. W.: Thermal and suprathermal ion observations in the low altitude transverse ion energization region, Geophys. Res. Lett., 18, 725-728, 1991.

Ungstrup, E., Klumpar, D. M., and Heikkila, W. J.: Heating of ions to superthermal energies in the topside ionosphere by electrostatic ion cyclotron waves, J. Geophys. Res., 84, 4289-4296, 1979.

Yau, A. W., Beckwith, P. H., Peterson, W. K., and Shelly, E. G.: Long-term (solar cycle) and seasonal variations of upflowing ionospheric ion events at DE1 altitudes, J. Geophys. Res., 90, 6395-6407, 1985. 